\section{Cruise Ship Olympic Surveillance System}

The Cruise Ship Olympic Surveillance System (CSOSS) is designed to enhance the existing notifiable diseases reporting system, and to actively identify unusual patterns of illness and disease on cruise ships. This surveillance mechanism builds on a reporting system operated by the South Eastern Sydney Public Health Unit and Sydneybased cruise vessel operators.

During the Games, cruise ship medical staff will be requested to complete an Olympic Cruise Ship Daily Medical Report for inclusion into the NSW Department of Health's OHSS. This daily report outlines the number of passengers on each ship, the number of medical consultations, hospitalisations, deaths and cases with the following specific symptoms and conditions:

- influenza-like illness

- suspected pneumonia

- gastroenteritis.

The summary report forms will be faxed daily to the Department of Health, and analysed and reported through the NSW Health Olympic Coordinating Centre (HOCC). The Olympic Medical Epidemiologist will be notified immediately of any acute health concerns or cases showing unusual symptoms of possible public health significance.

The large number of cruise ships that will converge in Sydney for the Sydney 2000 Olympic and Paralympic Games has presented a unique opportunity to develop and test a comprehensive system for surveillance of health on these vessels. It is hoped that the Sydney experience will inform planning for the next Olympic Games in Athens in 2004 , which will be serviced by a much greater number of cruise ships.

\section{ACKNOWLEDGEMENTS}

Peter Waples is currently participating in the NSW Public Health Officer Training Program. The authors would like to thank Paul Paraskevopoulos for his involvement in developing the cruise ship medical reporting system.

\section{REFERENCES}

1. Jerninigan DB, Hofmann J, Cetron MS, Genese CA. Outbreak of Legionnaires' disease among cruise ship passengers exposed to a contaminated whirlpool spa. Lancet 1996; 347: 494-99.

2. Distasio AJ. The investigation of a tuberculosis outbreak in the closed environment of a US Navy ship, 1987. Mil Med 1990; 155: 347-351.

3. Christenson B, Lidin-Janson G, Kallings I. Outbreak of respiratory illness on board a ship cruising to ports in southern Europe and northern Africa. J Infect 1987; 14: 247-54.

4. O'Mahony M, Noah ND, Evans B, Harper D. An outbreak of gastroenteritis on a passenger cruise ship. Journal of Hygiene 1986; 87: 229-36.

5. Waterman SH, Demarcus TA, Wells JG, Blake PA. Staphylococcal food poisoning on a cruise ship. Epidemiol Infect 1987; 99: 349-353.

6. Gupta L, Towler B, Frommer M. Investigation of an outbreak of gastroenteritis on a container ship returning from Asia. NSW Public Health Bulletin 1994; 5(6): 61-62

7. Ferson MJ, Paraskevopoulos P, Hatzi S, Yankos P, Fennell M, Condylios A. Presumptive summer influenza A: an outbreak on a trans-Tasman cruise. Commun Dis Intell 2000; 24: 45-47.

\title{
FOOD SAFETY MANAGEMENT AT OLYMPIC VENUES DURING THE SYDNEY 2000 OLYMPIC AND PARALYMPIC GAMES
}

\author{
Steve Holroyd, John Shields and Peter Waples \\ Olympic Planning Unit \\ NSW Department of Health
}

Ensuring food safety is a key element in the success of the Sydney 2000 Olympic and Paralympic Games (the Games). A major food-borne disease outbreak has been identified as one of the leading threats to public safety. In terms of the food quantities required for an event such as the Games, estimates suggest that 1.8 million meals will be served to athletes and officials and one million meals will be prepared for staff. Given the enormity of the task, the Food Safety Strategy for the Games has been in development since 1996. 'Prevention rather than cure' and inter-agency cooperation are the key themes of the plan. In the past few years, the food safety team has worked closely with the Olympic organisers (SOCOG) and other government bodies to increase awareness of food safety.

\section{THE ATLANTA EXPERIENCE}

During the 1996 Atlanta Olympic Games over 5,000 food safety inspections were conducted at Olympic venues. ${ }^{1}$ More than 100 illegal food operations were closed down and over seven tonnes of food destroyed. The maintenance of this intense inspection schedule was considered to be a key contributing factor to the absence of any reported food-borne illness outbreak. The inspections were aided by special government legislation that put tight controls on the practices of temporary food premises. There was 24-hour coverage of the Olympic Village. ${ }^{1}$

\section{OPERATION FOODWATCH}

Outside Olympic venues, Operation Foodwatch will play an important role in minimising the occurrence of food- 
borne illness during the period that Sydney will host the Games.

Operation Foodwatch is a program of enhanced food hygiene surveillance for food premises in the public domain. Local Councils and Public Health Units throughout greater Metropolitan Sydney report to a centrally-located database, which has been operating since early 1999. The information gathered by this system is used to categorise food premises, based on inspection histories. This information is used to target high risk outlets for more intensive inspection and follow up.

\section{THE SYDNEY 2000 OLYMPIC GAMES PLAN}

The Food Safety Strategy for Olympic venues involves the following actions:

- specification of special food hygiene conditions in SOCOG contracts and the highlighting of statutory obligations (for example, contractual obligations placed on Olympic venue caterers include the requirements that Hazard Analysis and Critical Control Point, or HACCP, Food Safety Plans be in place); ${ }^{2}$

- identification of all contracted food operations located within Olympic venues;

- allocation of a broad food safety risk rating (high, medium or low risk) to each food service outlet, according to whether they are serving potentially hazardous food types;

- coordination of ongoing site inspections and hygiene compliance checks and audits at all venues;

- recording of all food safety surveillance activities and central collation of data including daily summary reporting;

- implementation of the Strategy at test events prior to the Games to trial the inspection process and, if necessary, refine and enhance it.
Some of the key tasks in monitoring venue-based food operations will include:

- ongoing inspections of food premises and outlets to ensure compliance with food hygiene standards

- routine inspection of delivery and distribution vehicles

- selective sampling and testing of foods

- investigation of complaints received from the general public

- active surveillance for food-borne disease outbreaks.

\section{FOOD SAFETY WORKFORCE}

The Olympic food safety workforce will be drawn from both local government and NSW Health. Food safety surveillance personnel will implement the actions identified in the Food Safety Strategy for the 15 venues located within Sydney Olympic Park. Local government officers and food inspectors from area health service public health units will carry out food surveillance work in the 14 competition venues within the Sydney East, Darling Harbour and Sydney West Olympic Precincts. This workforce will operate during the pre-Olympic, Olympic and Paralympic periods in September and October 2000.

The detailed planning underpinning the Olympic Food Safety Strategy, and the strong collaborative approach between NSW Health and Local Government in implementing it, should minimise food-borne illnesses during the Games.

\section{REFERENCES}

1. Maria Visotina. Health and Medical Services for the Centennial Olympic Games Atlanta Georgia. Unpublished Report. Sydney: NSW Department of Health, 1996.

2. Codex Alimentarius Commission. Joint WHO-FAO Hazard Analysis and Critical Control Point System for food safety, 1993.

3. The Food Safety Strategy for the Sydney 2000 Olympic and Paralympic Games. Sydney: NSW Department of Health, 2000.

\section{COORDINATING PUBLIC HEALTH SERVICES AT OLYMPIC VENUES DURING THE SYDNEY 2000 OLYMPIC AND PARALYMPIC GAMES}

\section{Sarah Thackway}

Surveillance Manager, Olympic Planning Unit

NSW Department of Health

\section{Tim Owen}

Public Health Officer,

NSW Public Health Officer Training Program

NSW Department of Health

NSW Health is responsible for providing public health services to support Olympic and Paralympic venues under
SOCOG's jurisdiction. These include:

- competition venues

- residential areas:

- athletes village

- Olympic 'Family' hotels mainly in the central business district of Sydney

- media village at Lidcombe

- youth camp at St Joseph's College at Hunters Hill 